University for Business and Technology in Kosovo

UBT Knowledge Center

UBT International Conference

2017 UBT International Conference

Oct 28th, 4:00 PM - 5:50 PM

\title{
P.M. 2.5 and Air Pollution in Prishtina
}

Rushiti Bardh

University for Business and Technology, br39442@ubt-uni.net

Futko Annea

University for Business and Technology

Zeka Blin

University for Business and Technology

Musliu Afete

University for Business and Technology

Follow this and additional works at: https://knowledgecenter.ubt-uni.net/conference

Part of the Civil Engineering Commons

\section{Recommended Citation}

Bardh, Rushiti; Annea, Futko; Blin, Zeka; and Afete, Musliu, "P.M. 2.5 and Air Pollution in Prishtina" (2017). UBT International Conference. 48.

https://knowledgecenter.ubt-uni.net/conference/2017/all-events/48

This Event is brought to you for free and open access by the Publication and Journals at UBT Knowledge Center. It has been accepted for inclusion in UBT International Conference by an authorized administrator of UBT Knowledge Center. For more information, please contact knowledge.center@ubt-uni.net. 


\title{
P.M. 2.5 and Air Pollution in Prishtina
}

\author{
Bardh Rushiti \\ UBT - Higher Education Institution, Prishtinë, Kosovë \\ br39442@ubt-uni.net
}

\begin{abstract}
High concentration of fine particles, the primary concern of worsening air pollution in Prishtina is believed to be fast paced economic and infrastructural growth in the capital of Kosova. This study is mainly focused on measuring the fluctuations of one constituent of air pollution, P.M. 2.5 (which are particles ranging from 2.5 to 10 micro-meters suspended into the environment). The measurements were done in Prishtina, mainly in the parts more frequented by people. Exposed to mixed combustion emission from roads with traffic, construction areas, and/or burning trash are a case of peculiar concern to people near those places. However, due to Kosovo's continental climate, the fluctuations of these micro particles vary during different seasons throughout the year. The results have shown that during winter the levels of P.M. 2.5 skyrockets, due to the heating systems used by individual households; on the other hand. During summer, these levels appear normal, under the international standards. Consequently, from measuring the maximum and the minimum of P.M. 2.5, we can infer the causes of the increase and decrease during different seasons.
\end{abstract}

Keywords: Security, Web application, Exploit, Cross site

\section{Introduction}

Air pollution, as a general term, refers to various chemicals that are present in the air that might cause harm to living creatures on Earth. These chemicals may consist of gases, liquid and solid particles that remain in the air after being emitted by different sources. Indoor air pollution and poor urban air quality are listed as two of the world's worst toxic pollution problems in 2008. Unfortunately, both of these issues are very prevalent in Kosovo's capital, Prishtina. As the most frequented city in Kosova, the N.G.O. PEN, has decided, in accordance with Science for Change Kosovo, to implement a project whose main goal is to measure a particular constituent of air pollution, P.M. 2.5.

P.M. 2.5 is referring to particulate matter; or in other words, particles starting from $2.5 \mu \mathrm{m} / \mathrm{m}^{3}$ or less that are suspended into the environment by different sources. Some of the most dominant sources that we might come through in Prishtina are: old cars, burning trash cans, construction areas, roads with traffic, etc 


\title{
Measurements in Prishtina
}

The measurements targeted frequented areas, indoor spaces, schools, main roads, and nurseries, throughout the year. In other words, the measurements were done consistently in order to discover previously undetected indicators and causes of the inflation in P.M. 2.5:

\author{
1. Indoor Spaces \\ 2. Schools \\ 3. Main Roads \\ 4. Obilic \\ 5. Bio-indicators
}

These measurements will be described briefly in the following paragraphs.

\section{Indoor Spaces}

Two peculiar characteristic about P.M. 2.5 is that it floats above ground and when there's no wind or movement in an indoor area, it stays there up to 6 hours. Additionally, another reason we chose indoor spaces is because most of buildings in Prishtina are relatively old, and therefore lack proper ventilation.

After measurements, we found out that the levels of particulate matter in indoor areas high. In other words, when the levels outside, during a spring day were approximately $9-12 \mu \mathrm{m} / \mathrm{m}^{3}$, indoors it went up to $40-43 \mu \mathrm{m} / \mathrm{m}^{3}$

\section{Schools}

Generally, young adults, children and people with breathing problems are the most vulnerable during periods of high P.M. 2.5 levels; the reason behind this is because they are either too young and their lungs are not yet fully developed, or they have problems with people. Since Kosovo is known for the youngest population, we focused our measurements in "Faik Konica" middle school, which is located in center of Prishtina. We tracked all the roads that led to this school, to better understand the path children have to walk to go to school, and see which particular places are more polluted.

Additionally, as mentioned above, indoor spaces are old and polluted, due to lack of ventilation; however, the school workers, open all the windows and doors in order to do a natural ventilation of the whole place before the day starts, and therefore, the measurements showed a pretty low levels, compared to other institutions.

\section{Main Roads}

Having in mind that Prishtina is overpopulated by vehicles, the necessity for roads and parking spots is always in demand. This overpopulation is creating long traffic hours, and consequently, worsening the overall air pollution in Prishtina. From the places with the highest P.M. 2.5 levels, main roads are nearly at the top of the list. Average levels, regardless of weather, are higher compared to other locations. Unfortunately, most of student dorms are built near these roads, making the impact of air pollution worse. 


\section{Obilic}

Obilic is a small town not far from Prishtina. It is notoriously known for two power plants: Kosova A and Kosova B. Built 50-70 years ago, both of them supply Prishtina, surrounding towns, and villages with electricity. Even though the power plans have filters to prevent the smoke from roaming free, the filters are old; thus, do not do the job properly (based on local people's information). Surprisingly, based on the measurements, the levels of P.M. 2.5 are normal, with just instances of increase.

We have discovered that when there's no wind, this smoke goes to neighboring villages, and when the wind blows (usually south) it brings all the smoke to Prishtina. Also, geographically, Obilic has higher altitude than Prishtina; consequently, the smoke, flows down to there.

\section{Bio-indicators}

A bio-indicator is a living organism that gives us an idea of the health of an ecosystem. Some organisms are very sensitive to pollution in their environment, so if the pollutants are present, the organism may change morph-physiology or behavior, or it could even die. One part of the project was to measure air pollution with bio-indicators, to understand the condition of air pollution better.

The hardy lichens are useful bio-indicators for air pollution, since they derive their water and essential nutrients mainly from the atmosphere, rather than soil. The more diverse the lichens in a tree, the cleaner is the air. In locations, nearer to pollutants the diversity and abundance of lichens was very low, and this is how we got a clearer picture of the air pollution and polluted locations in Prishtina, and neighboring towns and villages.

\section{Measurements in the Winter}

As it can be inferred from observation studies, the fluctuations of P.M. 2.5 throughout winter are particularly higher compared to other seasons; even though more vehicles are present in the road, this is not the reason behind these fluctuations. Since Kosova has continental weather, the summers here are very hot, and the winters are very cold; therefore, we need more coal, wood, and other derivatives to warm the houses. Only after months of consistent and periodic measurements, we found out that the cause of this increase in P.M. 2.5 levels were individual households and their heating systems.

In the end of November and beginning of December, 2016 P.M. levels reached a different level of high. During that period the levels were above $90 \mu \mathrm{m} / \mathrm{m}^{3}$ (by the standard of the W.H.O. means that it has reached dangerous levels) and the Smog had covered the whole city. Smog is a kind of air pollution which results from large amounts of coal burning in an area and is caused by a mixture of smoke and sulfur dioxide. During that time there was an epidemic in Prishtina, a large amount of people were sick, and were experiencing symptoms of lowered immune system. 


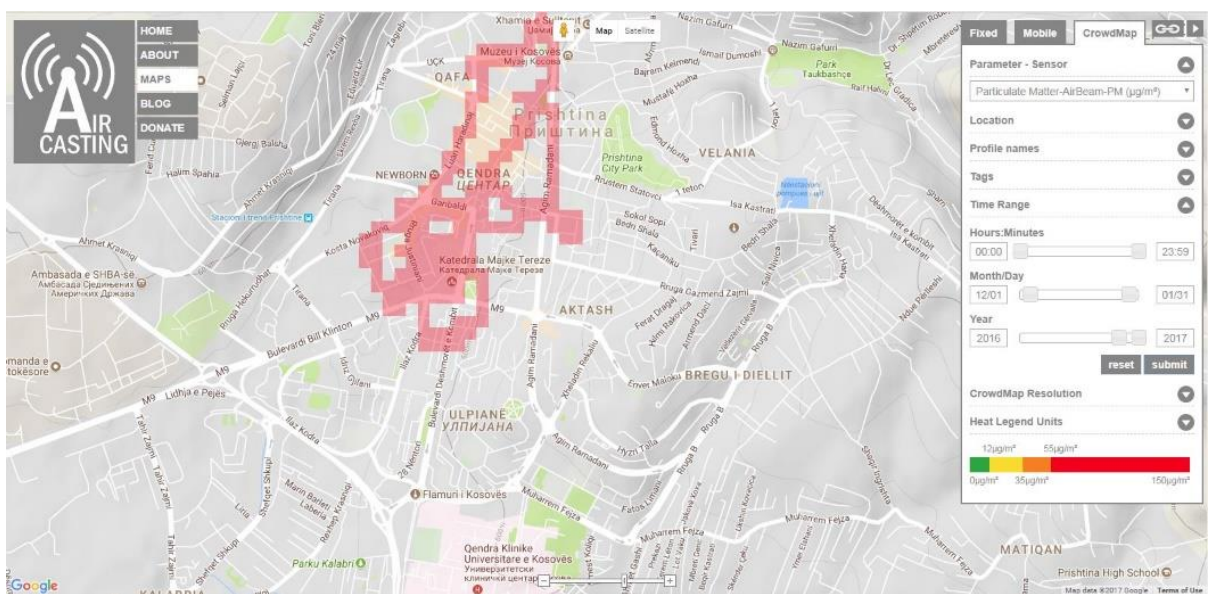

Fig. 1. Shows the measurements of P.M. 2.5 from Dec. 2016 - Jan. 2017

\section{Raising Awareness}

The first step towards solving every problem, is making the problem known. Our duty, as committee members of Making Sense Project, is to raise awareness of the air pollution problems in Prishtina, and all around Kosovo. And once the people know about it, it is in the hands of the citizens to make the change. We have created campaigns, marches, and informal classes to students to better inform them regarding the air pollution and similar problems in our community.

Additionally, Making Sense in launching a new application in order to raise awareness regarding air pollution. This application will show the graphs, minimum, maximum, in other words, it will analyze the measurements and will provide the best way for the citizens to comprehend.

\section{Conclusion}

Considering that Prishtina is an always growing city, air pollution is very prevalent. Making Sense Project has targeted P.M. 2.5 pollution and their causes. Doing the measurements systematically, in static and mobile locations (locations such as: schools, institutions, near main roads, squares, Obilic, etc.) and trying different approaches to better understand the situation, we came to the conclusion that P.M. 2.5 levels are present, and during winter, at alarming levels. We have used various ways to teach the citizens of this present pollution. Once they know about the problem, it is in their hands, as the mass, to win over this obstacle. 


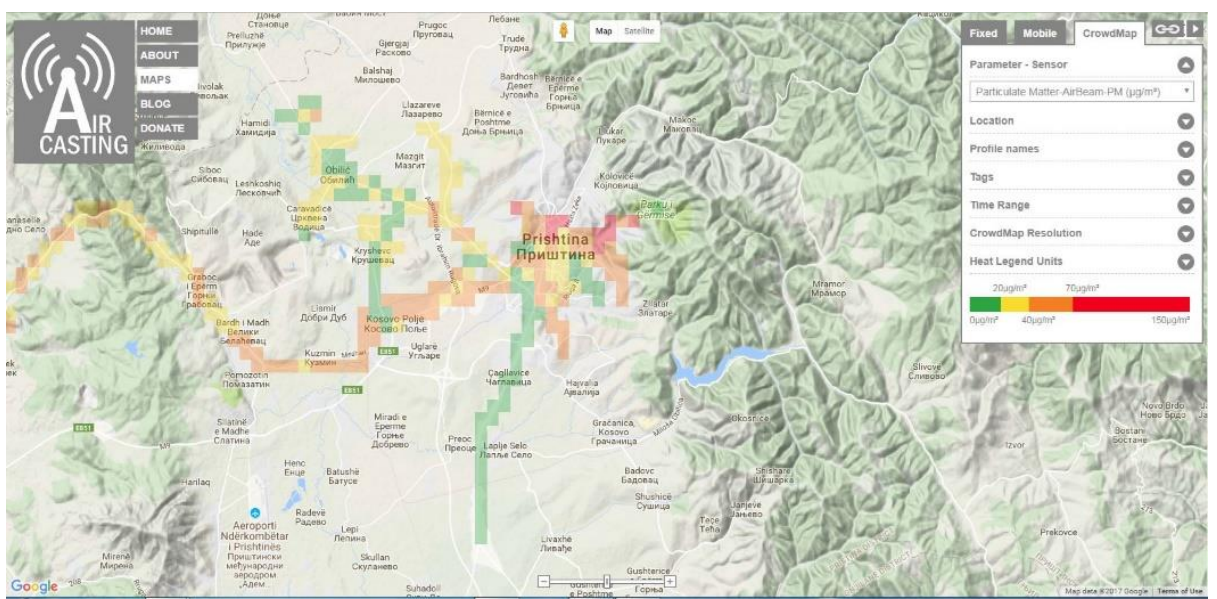

Fig. 2. All the measurements done by the Making Sense Project

\section{References}

1. Making Sense Project - Crowd Map Measurement, Available:

2. http://aircasting.org/

3. AirNow. "Particle Pollution," Available:

4. https://airnow.gov/index.cfm?action=aqibasics.particle

5. BioIndicators, Available: https://www.sciencelearn.org.nz/resources/1538-bioindicators

6. Smog, Available: https://en.wikipedia.org/wiki/Smog 